\title{
Pseudohypoparathyroidism masquerading as seizures since childhood
}

\section{Vijayasingham S, Doraiswamy A, Syed Alwi SOF, Mohamad R \\ Department of Medicine, Hospital Melaka, \\ Melaka, Malaysia}

\section{INTRODUCTION}

Pseudohypoparathyroidism (PHP) refers to a group of rare sporadic or inherited disorders characterized by parathyroid hormone (PTH) resistance. We report a case of PHP with phenotypical expression and multiple hormonal resistance.

\section{CASE DESCRIPTION}

We report a 26 year old lady who presented to us after a fall, with history of recurrent seizures since 12 years of age. There was a history of oligomennorhoea. Physical examination revealed round faced, short-statured (Figure 2a), obese (BMI 31) dysmorphic lady with subnormal intelligence and brachymetacarpia . Laboratory work up revealed hypocalcemia with a corrected calcium of $1.4 \mathrm{mmol} / 1$, phosphate $1.98 \mathrm{mmol} / 1$, iPTH $366 \mathrm{pg} / \mathrm{ml}$ (Table 1). CT brain revealed intracranial calcification (Figure 1). Skull radiograph showed scalp calcifications (Figure 3). Hand radiograph showed shortened $4^{\text {th }}$ metacarpals (Figure 4). She was managed symptomatically with intravenous calcium initially and commenced on calcium and vitamin D replacement. Further work up revealed hypothyroidism (FT4 $10.4 \mathrm{pmol} / \mathrm{l} \mathrm{TSH} 20.73 \mathrm{mIU} / \mathrm{L}$ ). On follow up she reported no seizures and was eucalcaemic. The elevated PTH in our patient with chronic hypocalcaemia, hyperphosphatemia, normal renal function and phenotypic features suggested pseudohypoparathyroidism type Ia (PHP-Ia).

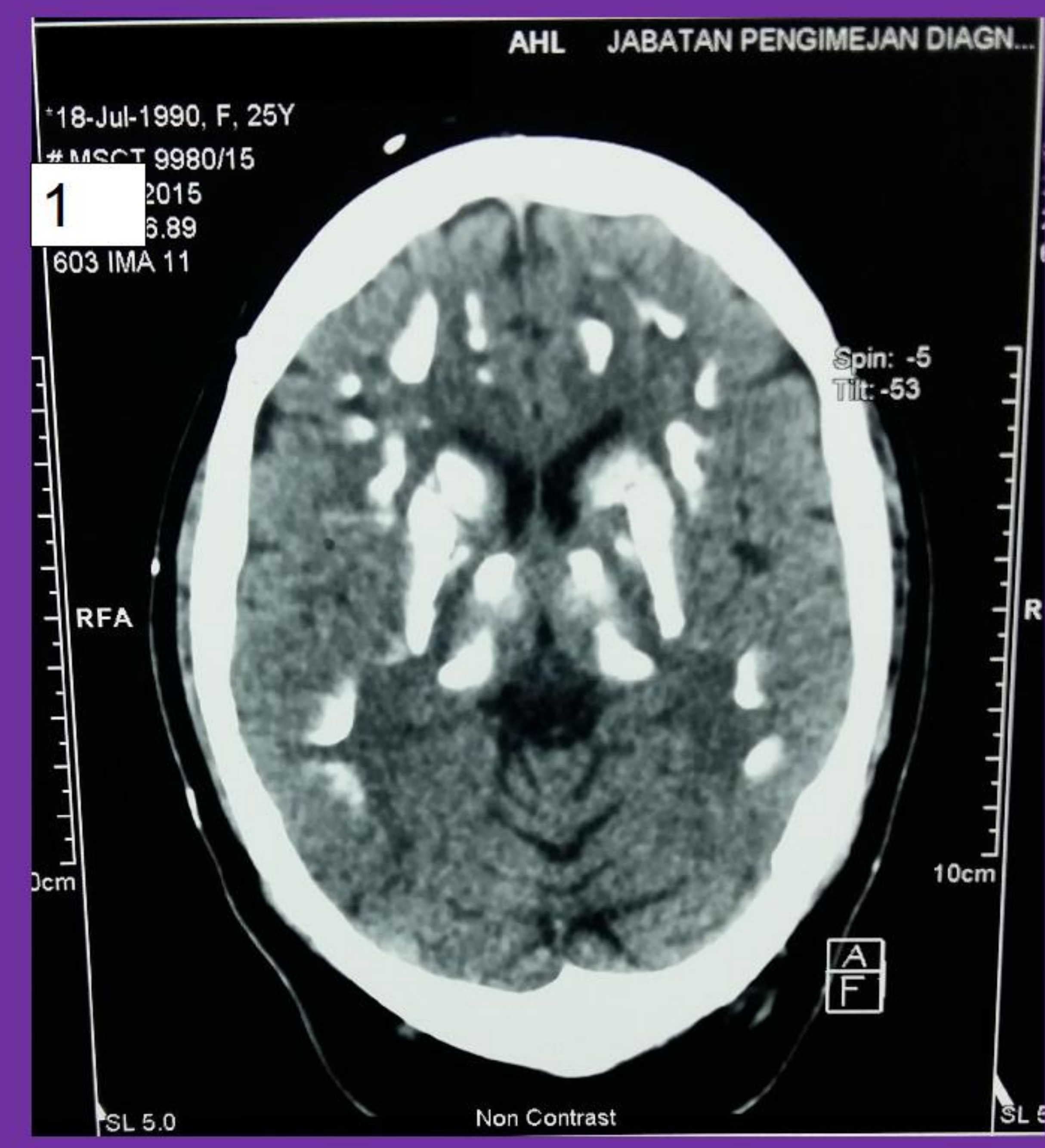

\begin{tabular}{|l|c|c|}
\hline $\begin{array}{l}\text { TABLE 1: } \\
\text { LAB } \\
\text { INVESTIGATION }\end{array}$ & ON ADMISSION & $\begin{array}{c}\text { ON } \\
\text { FOLLOW UP }\end{array}$ \\
\hline Serum iPTH(pg/ml) & 366 & - \\
\hline $\begin{array}{l}\text { Corrected Calcium } \\
\text { (mmol/L) }\end{array}$ & 1.42 & 2.04 \\
\hline $\begin{array}{l}\text { Inorganic } \\
\text { Phosphate } \\
\text { (mmol/L) }\end{array}$ & 1.98 & 1.58 \\
\hline \begin{tabular}{l} 
TT4 (pmol/L) \\
\hline TSH (mIU/L)
\end{tabular} & 10.44 & 21.68 \\
\hline $\begin{array}{l}\text { Anti- } \\
\text { Thyroperoxidase }\end{array}$ & 20.73 & 0.09 \\
\hline FSH (IU/IL & - & Negative \\
\hline LH (U/L) & - & 8.8 \\
\hline Oestradiol (pmol/L) & - & 188.6 \\
\hline
\end{tabular}
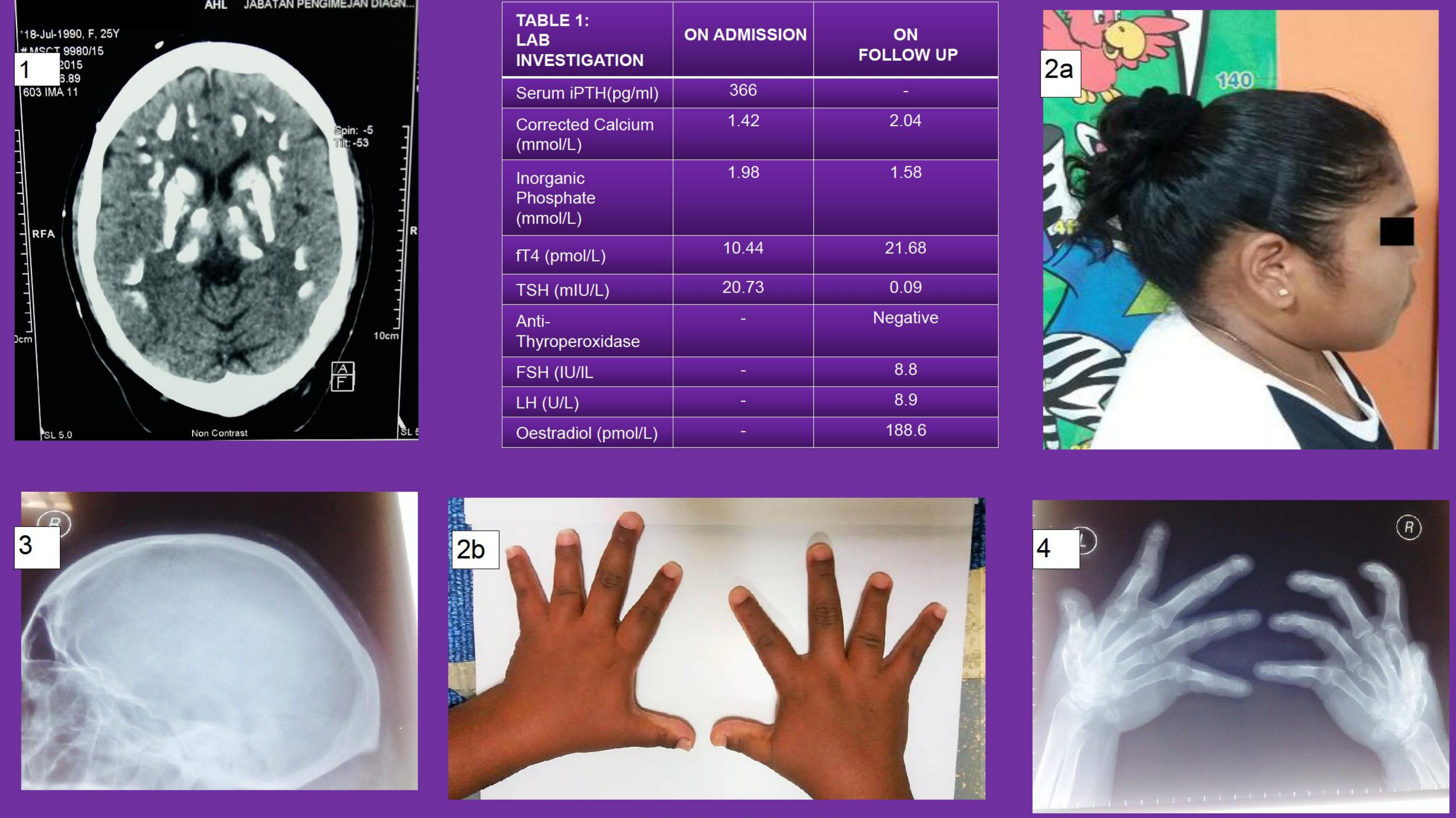

\section{DISCUSSION}

PHP is a complex disorder and diagnosis is often delayed. This was the case in our patient whose initial manifestation was seizures occurring during pubertal growth spurt corresponding to the higher calcium demand. The estimated prevalence in Japan (of PHP type la and $1 \mathrm{~b}$ ) is $1 / 295,000$. PHP-la is characterized by resistance to PTH and other hormones that stimulate adenyl cyclase in their target tissues, such as TSH, gonadotropins and GHRH. Primary hypothyroidism and reproductive dysfunction are commonly seen in these patients. Our patient did in fact have hypothyroidism. Heterozygous mutations in the GNAS1 gene, that encodes Gs $\alpha$, when inherited from the maternal allele are associated with the clinical loss of function and hormonal resistance. Patient with inactive or decreased amounts of Gs $\alpha$ showing phenotypic and biochemical features are diagnosed as PHP type 1, similar to our case. Our patient thus presents as a rare case of PHP-1a with multiple hormone resistance with typical phenotypic expression. 